\title{
A ORGANIZAÇÃO DO ESQUECIMENTO. HISTORIADORES PERSEGUIDOS E CENSURADOS NA ÁFRICA, ÁSIA EAMÉRICA LATINA
}

\author{
Antoon de Baets * - Depto. de História - University of Groningen - Holanda
}

\section{Introdução}

\author{
"Ou é verdade que uına naçāo não pode atravessar um \\ deserto de esquecimento organizado?" \\ Milan Kundera \\ O livro do riso e do esquecimento \\ (Londres, 1982, p. 159)
}

Este relatório inclui informaçōes sobre a censura da história e o destino de 360 historiadores perseguidos em quase 70 países no período de 1945- 1995. Deve ser visto como um instrumento contra duas formas de esquecimento.

Os historiadores precisam ter $\mathrm{em}$ mente a coragem que muitos de seus colegas demonstram quando tentam se dedicar à escrita da história sob a égide de um poder tirânico que descja impor sua visão do passado, à custa da supressão de todas as outras. Eles têm sido alvo de censura, demissão, exílio, aprisionamento, tortura e execução. Este relatório é um apelo diri-

* Traduçāo Nanci Leonzo, Professora do Depto. de História da FFLCH/USP e membro do Grupo de Trabalho da Nenwork of Concerned Historians ( $\mathrm{NCH}$ ). gido à comunidade internacional de historiadores para conscientizá-la da necessidade de combater a perseguição de seus membros, o que deve ser feito através de uma ação conjunta com as organizações de direitos humanos já atuantes nesta campanha.

O passado nāo é monopólio dos historiadores. Os cidadāos que lhe dão importância têm a obrigaçāo de lutar contra as tentativas de sepultamento daqueles episódios vistos como inoportunos pelas autoridades constituídas. O acesso à história é um direito individual e colctivo. Todo aquele que persegue este direito assume um compromisso com a verdade, mesmo que esta seja impopular ou dolorosa. A verdade histórica, entretanto, 6 inatingível e a absoluta, companheira do esquecimento.

Nem o passado, nem os historiadores que ousam desvendá-lo devem cair no esquecimento. Assim, este relatório é dedicado à memória de todos os historiadores e cidadāos envolvidos de algum modo com o passado e que lutaram pelo direito de escrever a história, algumas vezes colocando em risco sua própria vida. 


\section{Notas metodológicas}

A censura da historia apresenta-se, neste relat6rio, como o controle sistemático de conteúdos, informaçōes e idéias referentes ao passado imposto pelas autoridades em exercício ou, $\mathrm{cm}$ alguns casos, com sua conivência'. Esta forma de censura pode ter como alvo um trabalho histórico, em qualquer de seus estágios, scu produtor e até mesmo seus consumidores. O relatório, contudo, não engloba manifestaçõcs de propaganda histórica, que correspondem a manipulações sistemáticas de informaçōes relativas a esse passado. A propaganda histórica é um fenômeno muito amplo, de difícil comprovação. Embora na prática propaganda e censura tenham o propósito de silenciar a crítica, há uma diferença crucial entre ambas: enquanto a propaganda tenta impor uma visão do passado através da manipulaçāo ou - o que é hoje muito freqüente - da difusão de mentiras, a censura busca suprimir todas as visōes alternativas, utilizando o controle e recorrendo, por vezes - como o fez nos tempos recentes - à violência. Em outras palavras: a propaganda nāo implica, necessariamente, a censura, mas a censura é sempre acompanhada pela propaganda.

É importante compreender que quando o objetivo é o controle do passado, o censor se ocupa de todos os produtores de história, quer sejam eles profissionais ou nāo, interessando-se também pelas interpretaçōes desse passado $\mathrm{em}$ suas formas escritas, orais e visuais. Na verdade, o relatório demonstra que a história não acadêmica é mais visada pela censura do que a acadêmica, e provavelmente muito mais.

I. Esta definiçăo inspira-sc nas definiçōes gerais đe censura discutidas por S. Hanpshire e L. Blom-Cooper, "Censorhip?", Index on Censorship, 4:55, 1977 e H. Scannell, "Censorship and its History: a Personal View", In: Information. Freedom and Censorship: The Aricle 19 World Report 1988, London, K. Boyle and M. Piette, 1988.
Assim, uma definição flexível do termo "historiador" torna-se necessária. Ele é aqui utilizado para designar, de um lado, todos os que atuam no campo histórico (historiadores, arquivistas, arqueólogos e também estudantes de história) e, de outro, todos os autores de trabalhos históricos acadêmicos e não acadêmicos, independentemente de sua instruçāo ou profissão (jornalistas, políticos ctc.). Embora ampla, esta definição não engloba o trabalho regular dos jornalistas. Admite-se, entretanto, que este trabalho algumas vezes chamado "o primeiro registro em estado bruto da história" - tem um valor importante no sentido indireto: a censura da imprensa afetará o volume $\mathrm{c}$ a quantidade de fontes disponíveis para os futuros historiadores.

Não obstante a censura da imprensa seja um fenômeno peculiar a várias épocas e locais, este relatório apresenta dados referentes apenas aos últimos cinqüenta anos (1945-1995) e que dizem respeito aos chamados países não ocidentais da América Latina, África, Oriente Mćdio, Ásia e Oceania. Contuđo, é parte integrante de um projeto que abrange todas as áreas geográficas restantes. Diante disto, cabe esclarecer que a ausência de qualquer dado sobre um país em particular não significa que a censura da história deixou de ocorrer. Como regra, levou-se em conta somente as informaçōes explícitas, inclusive quando surgiram cntraves para comprovação. Isto significa que as informações sobre a censura de categorias mais amplas do que a dos historiadores (como a dos intelectuais), que podem incluir estes últimos, mas necessariamente não o fazem, foram inseridas mediante a coleta de um número suficiente de evidências que as sustentassem. Este é o caso de muitos países. Da mesma maneira, o espaço concedido a um país em particular, tendo em vista o número de casos arrolados, não pode ser considerado um índex da perseguição.

As informações foram inseridas no relatório com base no país responsável pela perseguiçāo, 
desconsiderando-se, assim, o país de origem do historiador, bem como aquele onde sofreu as consequiências da perseguição ${ }^{2}$. Casos anteriores a 1945 não estāo incluídos. É tudo o que foi possível obter até 01 de julho de 1995.

As evidências foram agrupadas $\mathrm{cm}$ três categorias:

Categoria A - Informações gerais sobre a censura da história.

Categoria B - Historiadores censurados ou perseguidos fora do campo histórico.

Categoria C - Historiadores censurados ou perseguidos dentro do campo histórico.

No interior de cada categoria todas as informaçōes foram organizadas em estrita ordem cronológica. Isto se tornou necessário devido ao grande espaço de tempo coberto $\mathrm{c}$, também, aos intervalos cntre os vários casos.

Categoria A - Contém informaçōes sobre a censura da história não referentes aos historiadores propriamente ditos.

Categoria B - Fornece informações sobre a perseguição de historiadores em razão de suas atividades fora do campo histórico. Esta categoria penmite que se tenha uma idéia dessas atividades e é, antes de tudo, uma modesta contribuiçāo para a história dos intelectuais. A história dos historiadores perseguidos é parte da história cultural. Entretanto; esta categoria foi inserida por outras razões. Quando os historiadores têm uma postura crítica com relaçāo aos scus estudos $\mathrm{c}$ ao mundo no qual vivem, suas incursões fora do campo histórico, por exemplo, na política, no jornalismo ou nos direitos humanos, são inspirados pe-

2. Como por exemplo o iraniano Alî Sharî̀'Atî, que morreu em Londres em circunstâncias misteriosas, ou o cidadão britônico Salman Rushdie, cuja cabeça foi colocada a prêmio pclo Ayalolá Khomeini, ambos catalogados sob "Irã". Esı regra, porém, tem duas exceçōes: ver África do Sul sob categoria A e Vietnā sob B. Aquì e em várias notas subseqüentes o Prof. Baets se refere a um texto que condensa informaçōes de todo o mundo (nota da tradutora).
Jos seus trabalhos dentro do próprio campo ${ }^{3}$. Nossos dados sugerem que isto acontece com freqüência, embora seja muito difícil comprovar a influência de concepções historicas concretas. Curiosamente, o inverso também é verdadeiro: políticos e jornalistas chegam, por vezes, à conclusão de que necessitam de uma sólida base histórica para seus trabalhos e assim se transformam $\mathrm{em}$ historiadores amadores. Há casos em que o processo de reflexão é ativado pela própria perseguição. $O$ aprisionamento e o exílio provocam um rompimento total com o tipo de vida até então levado e a maior quantidade de tempo inesperadamente disponível acaba gerando um estimulante interesse no passado, fato que, em condições favoráveis, conduz ao estudo e à escrita da história ${ }^{4}$. É notável como isto tem ocorrido. Em síntese: o trabalho histórico e outras atividades podem estar tão entrelaçados, que se torna impossível assinalar um motivo simples para a perseguiçāos. Assim, a categoria B e a categoria $\mathrm{C}$, algumas vezes, se sobrepõem.

Categoria C - Cobre os historiadores censurados e perseguidos pelo exercício de atividades dentro do campo histórico. Como esta é a categoria mais importante, o objetivo era o de elaborar um relatório o mais completo possível. Entretanto, ele está longe do descjado: muitas informações eram fragmentárias. Dúvidas sobre inserir ou não um caso foram geral-

3. Wang Dan (China) pode ser um exemplo.

4. Para a escrita da história no exílio: passim: para a escrita da história na prisão ver. por exemplo, Jawaharlal Nehru (Índia), Pramoedya Ananta Toer (Indonésia), Adolfo Gilly (México), Govan Mbeki (África do Sul), Jit Phumisak (Tailândia); para o ensino ou o relato da história na prisão ver. por exemplo, Fidel Castro (Cuba), Pramoedya Ananta Toer (Indonésia), Suleiman Mohamed Soail (Sudão). Estas reflexỏes sobre a história e o tempo. feitas nas prisōes, adquirem especial importância diante do fato de que os prisioneiros geralmente veêm a perda da noção de temporalidade como um dos maiores perigos da vida no cárcere; ver, por exemplo, Liana Benavides Grütter (Nicarágua).

5. Caio Prado Junior (Brasil), Albert Adu Boahen (Gana) e Walter Rodney (Guiana) podem ser exemplos. 
mente solucionadas em favor da simples inclusão. A imperfeição de certas evidências pode ser atribuída a muitas razōes:

$1^{\circ}$ - A censura freqüentemente toma o caráter de instrumento de tortura "menor", impondo restriçōes às carreiras. A repressão econômica e social, como a perda do emprego, o rebaixamento do grau acadêmico, a proibição de viagens ao exterior, bem como de contatos com especialistas estrangeiros, é, gcralmente, menos relatada do que a repressão física. Além disso, é possível que alguns historiadores prefiram que seus casos não sejam vistos como aqucles onde atuou a censura ou ocorreu a perseguição.

$2^{\circ}$ - A censura comumente desenvolve-se $\mathrm{cm}$ uma atmosfera de segredo.

$3^{\circ}$ - A censura tenta atingir o íntimo do historiador. Assim, a mais eficiente c muitíssimo difundida, porém menos visível, é a auto-censura. Além do mais, $\varepsilon$ difícil distinguir o historiador prudente, que prefere permanecer no anonimato, daquele que incorpora a auto-censura.

$4^{\circ}$ - Conforme já exposto, muitas informações não foram comprovadas. Em situações de repressão em larga escala, os historiadores estão certamente entre as vítimas, mas as informações que lhes dizem respeito são, geralmente, inaccssíveis ${ }^{\kappa}$.

$5^{\circ}$ - Quando a repressāo se prolonga por muitos anos, é difícil decidir se um historiador, que partiu para o exílio na infância e prosseguiu sua educaçāo no extcrior, deve ou não ser incluído ${ }^{7}$. É quase impossível descobrir se essa permanência fora do país natal foi voluntária ou não.

6. Cambodja de 1975 a 1979 c Uganda de 1971 a 1979 såo exemplos prováveis. Para Uganda ver A.A. Mazrui, "Subjetivism and the Study of Current History: Political, Psychological and Methodological Problems". In: The Methodology of Contemporary Africa. Paris, UNESCO. 1984, pp. 30-32.

7. Tsering Shakya (China) e um exemplo. Isto se aplica a vários historiadores tibetanos, curdos e armênios. $6^{\circ}$ - As organizações de direitos humanos s6 começaram a sistematizar a coleta de dados relevantes nos anos 70, em alguns casos, um pouco antes. Seus relatórios são nossas principais fontes de informa-

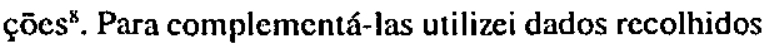
nos dicionários históricos e biográficos e nos estudos historiográficos. Consultei, também, os trabalhos censurados $\mathrm{e}$ as autobiografias dos historiadores vitimados. Isto, é claro, sempre que acessíveis. Embora estas fontes tragam ricas informaçōes em seu conjunto sāo, por vezes, lacunares, tornando-se difícil comprovar se um certo intclectual é ou não historiador e se o motivo conhecido da perseguição corresponde ao real.

Ressalto que, além da prova imperfeita e das ocorrências que não chegaram ao meu conhecimento, nenhuma tentativa foi feita no sentido de obter uma descrição dos modelos gcrais de repressão ou do clima geral de liberdade de expressão reinante durante a ocorrência dos casos individuais, mas mesmo assim, scmpre que possível, opcrci com alguns dados contextuais. Este relatório é, antes de mais nada, um cstudo de caso. Comparo os incidentes arrolados às

8. Quero agradecer as seguintes organizaçōes pelas inforInaçőcs c, sobretudo, pelo incentivo que deram: American Association for the Advancement of Science (Comitê sobre Liberdade Científica e Responsabilidade); Anistia Internscional, Artigo 19, Vigília dos Direitos Humanos, Index sobre a censura; PEN Internacional, Comite dos Escritores presos; UNESCO; Serviço da Universidade Mundial. Sou também muito grato aos colegas que contribuiram com sugestões: Victor Hugo Acuña Ortega, Pieter Boele Van Hensbroek, Inge Brinkman, Marc De Tollenaere, Michel Doortmont, H.A.J. Klooster, Cees KuiKen, Héctor Pérez Brignoli, Michael Riekenberg, Ingrid Sennema, Arturo Taracena Arriola, Daniel Woolf. Nos seminários sobre censura da história e temas correlatos, os quais tenho a oportunidade de dirigir, a partir de 1990, na Universidade de Groningen, foram muitas as discussōes estimulantes com meus alunos. Admirei o entusiasmo destes jovens. Meu trabalho teria sido impossivel sem a assistência do pessoal da biblioteca da Universidade de Groningen. Finalmente, quero registrar efusivos agradecimentos à minha colcga Ingrid Sennema que carinhosamentc revisou o texto. 
estrelas da noite: algumas delas (historiadores perseguidos) são visíveis, outras não, mas a observação do céu estrelado é um método válido de orientação na noite (o modelo geral de repressão "na retaguarda" do historiador).

Deve ser enfatizado que o relatório descreve somente um aspecto da vida dos historiadores e nāo oferece um quadro completo de suas atividades. $\mathrm{O}$ leitor deve consultar as fontes listadas nas notas para informaçōes mais detalhadas. É em geral difícil avaliar os motivos reais das escolhas que os historiadores fizeram em tempos de repressão e, assim, opiniōes sobre a resistência, o silêncio e a colaboração são raramente relevantes. Estudando os casos, senti, com freqüência, admiração pela coragem dos historiadores e qualidade de seus trabalhos históricos. Entretanto, quero deixar claro que não me solidarizo com os pontos de vista censurados e nem os sustento. Este princípio de distanciamento se aplica a todos os casos, mas pretendo ser mais incisivo em duas instâncias: $1^{\text {a }}$ ) diz respeito à perseguição de historiadores que haviam denunciado seus colegas. Mesmo assim, o relatório contém algumas informaçōes sobre alguns desses casos. Algumas vezes seus destinos atestam o capricho com que foi manipulada a propaganda histórica, outras revelam a pressão cruel cxercida sobre os historiadores para que delatassem seus/suas colegas $^{9} .2^{2}$ ) de natureza distinta; refere-se à censura da história falscada, como por exemplo, daquela que nega o Holocausto. Que tais abusos da história podem ser constatados, $\in$ fora de qualquer dúvida; se eles devem ser censurados, não é ${ }^{10}$.

9. Ver, por exemplo, China.

10. Ver, por exemplo, Namíbia. Sobre a questão da punição judicial a respeito da negaçāo do Holocausto ver: P. VidalNaquet, Assassins of Memory: Essays on the Denial of the Holocaust (originalmente França 1987; New York 1992) e JD. Bredin - "Le Droit, le Juge et l'Hístorien" e G. Kigman "L'Historie devant ses juges", ambos em Le Débat, november: $93-111$ e $112-125,1984$

\section{Vias de análise}

O relatório demonstra que a censura da história é comum e multifacetada, ocorrendo em contextos políticos e historiográficos amplamente divergentes. Alguns exemplos atestam que, apesar das lacunas acima discutidas, os dados permitem uma reflexão comparativa e também uma análise.

Observando o lado dos censores, somos imediatamente tentados a detectar preferências em suas estratégias. Em alguns países, a história contemporânea é certamente o período de estudo mais perigoso ${ }^{11}$; em outros, etapas remotas da história se constituem no foco da atenção oficial ${ }^{12}$. Mas há ainda aqueles nos quais as origens da nação ${ }^{13} \mathrm{e}$, ao mesmo tempo, as descobertas arqueológicas ${ }^{14}$ sāo os tópicos que geram suscetibilidades. Como expressōes vitais dessas estratégias temos o abandono e a destruição dos arquivos, assim como a imposição de obstáculos destinados a impedir o acesso dos pesquisadores que os procuram ${ }^{15}$. Uma forma muito eficiente de censura é a intimidação: alguns historiadores sofreram ataques em público por parte do Presidente, do Primeiro Mi-

11. Ver, por exemplo, Argentina (geral), Brasil (geral), Gana (Albert Adu Boahen), Japāo (Ienaga Saburó); México (geral); Nigéria (Kole Omotoso), Siria (geral), Zaire (geral); ver, também, F. Luna, "Oficio e Responsabilidad del Historiador en la Argentina de Hoy". Todo es Historia, 224: 89-90, 1985.

12. Ver, por exemplo, China (Wu Han e muitos outros); Índia (controvérsias sobre manuais cscolares).

13. Ver, por exemplo. Gu Jiegang (China) e como exemplo anterior à guerra o historiador japonês Tsuda Sôkichi (1873-1961). In: Lucien Boia (org.), Great Historians of the Modern Age: An Insernational Dictionary. New York, 1991, pp. 454-455.

14. Ver, por exemplo, Afeganistāo (Ralph Pinder Wilson); Etiopia (Desmond Clarke, Don Jonhansen); Líbia (geral), Rodésia (geral); Sudāo (geral e Osama Abdel Rahman al Nur e outros).

15. Ver, por exemplo, Argentina (geral); Egito (geral); Rodésia (geral); Turquia (geral); ver, também, Mazrui: 37-39, 1984. 
nistro ou de outros membros do $1^{\circ}$ escalāo $0^{16}$. A história não é certamente algo que causa indiferença aos mais altos dignatários. É extraordinário como muitos deles têm estudado a história, escrito trabalhos historicos ou demonstrado, de algum modo, um interesse especial pela história ${ }^{17}$. A história é também significativa para os grupos não oficiais. Uma característica surpreendente do relatório é a participação, em muitos países, de organizaçōes nāo governamentais, por vezes aliadas ao poder, em açöes de censura ${ }^{18}$.

Como é previsível, as reaçōes dos censurados são tão diversas como as estratégias dos censores. Os historiadores utilizaram cinco métodos principais para contornar a censura: mantiveram-se em silêncio, a!-

16. Ver, por exemplo, Eduardo Galeano, pelas autoridades argentinas na televisīo e na imprensa; Wu Han e Jian Bozan em discursos do Presidente do Conselho Mao Zedong (China): Walter Rodney pelo Primeiro Ministro Hugh Shearer em um debate transmitido ao vivo por toda a Jamaica: Thomas Karis, Tom Lodge, Mzala, Gerard Maré, Georgina Hamilton e Shula Marks, em discursos do Chefe Mangosuthu Buthelezi (África do Sul), Nabîh Aqil, por um membro da Assembléia Nacional (E.mirados Árabes Unidos).

17. Líderes com um título em história: Mangosuthu Buthelezi (África do Sui); Juan Natalicio Gonzales (Paraguai): Alpha Konaré (Mali); Leslie Manigat (Haiti); Julius Nyerere (Tanzania); Juan Perón (Argentina); Jânio Quadros (Brasil); Soekarno (Indonésia): Eric Williams (Trinidade e Tobago); e, de acordo com algumas fontes, Muammar al-Qaddafi (Líbia). Lideres que escreveram um trabalho ou proferiram importantes discursos com conteúdos históricos: Habib Bourguiba (Tunísia); Pierre Gemayel (Líbano): Ho Chi Minh (Vietnã): Joıno Kenyatta (Quênia); José Lópes Portillo (México): Mao Zedong (China); Jawaharlal Nehru (India); Turgut Özal (Turquia); Sadam Hussein (Iraque). Muitos líderes têm mostrado interesse em outras variantes: Ver, por exemplo, Fidel Castro (Cuba) neste relatório. Ver, tambem, A. de Baetes, "Heranten van cen Groots Verleden: de Geschiedvisie van DerdeWereldleiders (Heralds of a Glorious Past: the Historical Views of Third World Leaders)", Gronier: 6-21, 1994.

18. Ver, por exemplo, Egito (Farag Fouda, Said alAshmawi): India (Mushirul Hasan; Irfan Habib: M. Kalburgi: Sadique Hussain); 1srael/Líbano (Abudul Wahhab Kayyali); Japåo (Ienaga Saburô); África do Sul (Floris Van Jaarsveld); Sri Lanka (Sabarotnam Sabalingham): Sudão (Na'um Bey Shuquayr), Turquia (Server Tanilli); Emirados Árabes Unidos (Nabîh Aqil); Zâmbia (Robert Papstein). teraram (para "salvar") t6picos de pesquisas ${ }^{19}$, expressaram um posicionamento crítico indireto através do uso de analogias históricas ${ }^{20}$, optaram pela clandestinidade ou abandonaram o seu país ${ }^{21}$. Alguns mais corajosos seguiram outro caminho, isto ć, o confronto. Protestaram abertamente contra as tentativas de cerceamento da liberdade acadêmica e um deles processou o Estado $\mathrm{em}$ um famoso caso de manual escolar censurado"2. Não fugiram do conflito, pelo contrário, deixaram-se atrair pelos tabus oficiais. Poucos substituiram suas pesquisas por outras apoiadas em épocas e tópicos proibidos ${ }^{23}$. Em face a tais obstinações, a censura cvitou suprimir as visões alternativas, preferindo generalizá-las, abalando, assim, seus objetivos específicos. Além disso, estimulou canais alternativos capazes de disseminar as opiniōes dissidentes sobre o passado. Quando a história é alvo de censura, todas as outras formas de expres. são, até mesmo os grafitcs, tornam-se um veículo potencial de mensagens históricas. Algumas vezes, a censura da história exerce um importante papel hcurístico "ao contrário": atuando em favor da propaganda, deixa geralmente intacta a quantidade de passado possível, concentrando-se em interpretaçōes de temas vistos como fundamentais. Ironicamente, tal atitude adquire, com frequiência, o caráter de uma prova "ao contrário" da consciência histórica ${ }^{24}$.

19. Ver, por exemplo, China (geral): Egito (Abd alRahmân Zakî; Muhammad Sabrî; Muhammad Shafiq Ghurbâl).

20. Ver, por exemplo, China (passim); Indonésia (Promoedya Ananta Toer); Irã (Alî Sharî atî; Síria (geral).

21. Ver, por exemplo, Argentina (Emilio Ravignani e mui. tos outros); Paraguai (seis exemplos na categoria B).

22. Ver, por exemplo, Angentina (Enrique Barba); Brasil (Sérgio Buarque de Holanda); Japảo (lenaga Saburô).

23. Ver, por exemplo, Gana (Albert Adn Boahen), Japão (lenaga Saburô).

24. Ver como um claro exemplo: Malawi (A); ver, também, G. Baudot, "Conscience Historique et Ecriture de l'Histoire dans le Mexique Précolombien", Storia della Storiografia, 5:8, 1984. 
As açöes das autoridades e as respostas dos historiadores perdem seu caráter pessoal quando o conflito torna-se objeto de interesse público. O relatório fornece quatro exemplos de debates no domínio da "história não acadêmica" e no da "história escolar". Na verdade, é o amplo alcance da história da educação, fato que a transforma em um importante tema político. Controvérsias sobre manuaais de história ocorreram na Índia em 1977-78, no Japão em 1982, na Colômbia em 1989 e no México em $1992^{25}$. Nestes locais a imprensa foi o principal fórum das controvérsias e debates parlamentares sobre a história ensinada nas escolas tiveram lugar pelo menos nos dois primeiros. Por toda parte grandes grupos de historiadores foram convocados para expressar sua opiniãó. As controvérsias mereceram a atenção da censura em todos os países, com exceção do México, onde aparentemente desenvolvia-se mais um debate sobre a admissibilidade da propaganda oficial. No Japão adquiriram uṃa dimensão internacional em razão de outros países estarem interessados nio conteúdo histórico narrado nos manuais escolares japoneses.

A controvérsia se constituiu, em cada caso, como a manifestação mais visível de uma séria questão enraizada. $\mathrm{Na}$ Índia era o confronto entre visōes secundaristas e comunalistas da história, na Colômbia o combate entre visões conservadoras e progressistas da história, no Japão o litígio entre os que al: mejavam uma retratação positiva da história japone: sa e aqueles que pretendiam discutir seus espaços obscuros e, no México, o embate entre os que planejavam utilizar a história contemporânea para o controle partidário $\mathrm{c}$ aqueles que a isto resistiam. Na Índia e na Colômbia era, também, uma disputa entre metodologias tradicionais e modernas. Sérias discordâncias surgiram no que dizia respeito ao pe-

25. Ver apontamentos sobre estes quatro paises para mai: ores detalhes. rigo da substituição, nos manuais escolares, da história dos grandes homens pela das massas e do cotidiano. As controvérsias geradas pelos manuais escolares mostram claramente que a história torna-se um assunto de grande importância quando envolve o público em geral e as geraçōes futuras. Elas nāo refletem somente diferentes interpretações do passado, mas também, nos últimos tempos, diferentes concep-. ções básicas da identidade nacional.

\section{$O$ que podemos fazer?}

Este relatório demonstra que a história construída é importante e perigosa. Temos agora que nos perguntar o que os historiadores, cuja libērdade acadêmica não está em perigo, podem fazer para ajudar seus colegas perseguidos. A resposta é simples, mas suas razões são complexas. Devemos reunir esforços com as organizações de direitos humanos, as quais já se encontram em campanha. Antes de levar em conta as afinidades do trabalho em direitos humanos com aquele desempenhado pelo historiador, pode ser útil distinguir, de modo geral, três fases de tempo.

Primeira, há o "tempo da repressão", aquele no qual ocorre a violação dos direitos dos historiadores. Segunda, há o "tempo da memória", a extensão do tempo no qual o perseguido e seus contemporâneos recordam os maltratos passados. Terceira, há o "tempo da história", quando as vítimas e seus perpetradores estão mortos e a memória dos maustratos é mantida viva somente no trabalho dos historiadores. É claro que, de fase pàra fase, os esforços das organizações de direitos humanos geralmentc diminuem e os dos historiadores aumentam. Entretanto, os dois esforços se complementam.

Às organizaçōes de direitos humanos traḅalham pela liberdade de expressão para todos, incluindo historiadores e pessoas que desejari relembrar os maustratos sofridos. Além disso, fornecem parte das fontes materiais que serāo utilizadas pelos futuros his- 
toriadores que desejarem estudar o "tempo da repressão".

Os historiadores partilham, graças à sua ética profissional, com as vítimas da perseguição $e$ as organizações de direitos humanos um importante propósito: conhecer a verdade plena. A verdade historica é a extensāo natural da verdade perscguida pelas vítimas e seus aliados quando estes estão ainda vivos. Os historiadores devem estudar a história da perseguição. A responsabilidade social daquele que deseja ser fiel à realidade e goza de liberdade para atingir esta meta 6 tripla ${ }^{26}$.

É uma responsabilidade para com o passado porque a memória dos maus-tratos causados pelo poder e a luta contra eles travada têm de ser mantidos vivos. Quando os historiadores falham nesta tarefa, o "tempo da história" pode se tornar um "tempo de esquecimento e de negação". É também uma responsabilidade para com o presente porque as pesquisas contemporâneas sobre direitos humanos e os relatórios tomam como base um fundo histórico. Finalmente, é uma responsabilidade para com o futuro porque os historiadores podem contribuir cada vez mais para a conscientização sobre os direitos humanos, difundindo suas descobertas, isto é, publicandoas e ensinando-as.

Contudo, muitos historiadores não desejam esperar até que seus esforços profissionais se transformem em um patamar mais elevado de respeito aos direitos humanos. O presente relatório comprova que os historiadores se engajaram $\mathrm{em}$ atividades relacionadas com os direitos humanos durante o "tempo da repressão" e o "tempo da memória" ${ }^{27}$. Em algumas

26. Ver F. Bedarida. "The Social Responsability of the Historian", Diogenes: 168, 1994, especialmente pp. 2-3, 28 , 61, 74, 81-82.

27. A maioria delas pode ser encontrada na Categoria $B$ Ver, por exemplo, Afeganistão (Hasan Kahar): Brasil (Hermógenes da Silva Almeida Filho); Chile (Pablo Arturo Fuenzalida Zegers); África do Sul (David Webster). A carta ocasiōes os historiadores participaram de campanhas em prol de seus colegas censurados ou perseguido ${ }^{28}$.

O tempo tem dado a esses esforços uma base estrutural. Espero que a proposta abaixo seja discutida neste congresso ${ }^{29}$ :

1-O reconhecimento da Network of Concerned Historians como uma organização já pronta para campanhas de solidariedade.

2 - A constituição de um "Grupo de Trabalho", o qual deverá funcionar como um elo entre a Network e as organizações de direitos humanos, fornecendo informações sobre nossos colegas perseguidos. Tais informaçōes podem ser disseminadas por correio eletrônico ou fax. O autor deste relatório está preparado para aluar como um contato pessoal temporário e, também, como coordenador.

Com uma estrutura como esta, protestos podem. ser dirigidos às autoridades e contatos serão estabelecidos com os colegas perseguidos. Virá, assim, a oportunidade de divulgar seus escritos e convidá-los para palestras. Poderemos, também, auxiliá-los financeiramente, agregando-os a um corpo editorial ou, ainda, facilitando a publicação de seus principais trabalhos. Os casos arrolados serāo divulgados em boletins informativos, em jornais especializados ou durante ciclos de conferências, mesmo quando estas tenham lugar nos países responsáveis pela perseguição. Despertando a atençāo para tais casos, conseguiremos dar um pouco de imunidade e proteçāo aos

original da organizaçâo de direitos humanos "Carta 77 , da Tchecostováquia", obteve quarenta assinaturas, cerca de um sexto do total de historiadores. Ver K. Bartosek, "Les Historiens dans l'Histoire", La Nouvelle Alternative, 1:47, 1986.

28. Ver as controvérsias sobre livros escolares acima men. cionadas.

29. O autor refere-se ao $18^{\text {th }}$ Insernacional Congress of Historical Sciences, realizado em Montreal (Canadá), no período de 27 de agosto a 3 de setembro de 1995 (nota da tra. dutora). 
perseguidos. Finalmente, contribuiremos para que os governos tomem ciência de que seus atos não passam despercebidos e sem condenação no exterior ${ }^{30}$.

Há vinte anos atrás, o historiador tchecoslovaco Vilém Precan enviou uma Carta Aberta aos participantes do $14^{\text {th }}$ International Congress of Historical Sciences, que se realizava em São Francisco (USA). No ano de 1970 ele havia sido demitido do Historical Institute of the Academy of Sciences, na Tchecoslováquia, sob acusação de "irresponsabilidade política". Nesta carta de julho de 1975, escreveu: "Declaro que pretendo me realizar como ser humano $\mathrm{e}$ trabalhador no campo da ciência histórica em qualquer lugar do mundo, sob uma única condição: ti-

30. Ver "The Five Commandments", Index on Censorship, 1:17-18, 1975; American Association for the Advancement of Science, Directory of Persecuted Scientists, Engineers, and Health Professionals (Washington, 3-4, 1994). Ver também, The Lima Declaration on Academic Freedom and Autonomy of Institutions of Higher Educarion, Artigo 16: "Todas as instituiçb̄es de educação superior serão solidárias com aquelas cujos membros da comunidade acadêrnica săo alvo de perseguiçōes. Tal solidariedade pode ser moral oü material, incluindo refúgio, emprego ou educação para as vîtimas de tais arbitrariedades". In: World University Service, Academic Freedom 1990: A Human Rights Report (Londres, 189-190, 1990). berdade de investigação científica. Peço-lhes, estimados colegas, que sejam solidários e ajudem-me no que for possível. Digo isto claramente. Sem a solidariedade e o apoio de vocês, não terei chance de permanecer livre para prosseguir no meu trabalho como historiador"31. Vilém Precan foi para o exílio, na Alemanha Ocidental, em 1976.

Quando está em perigo o direito de nossos colegas exercerem, livremente, suas atividades como historiadores, todos nós corremos o risco de perder esse mesmo direito. Temos o dever de usar a liberdade acadêmica que desfrucamos em benefício daqueles a quem ela foi negada. Somente assim a organização do esquecimento poderá ser contestada com êxito.
31. Ver Precan, "Bound, Gagged and Robbed", Index on Censorship, 4:57, 1975; Original alemão em: V. Precan, Die Sieben Jahre von Prag 1969-1976: Briefe und Dokumente ans der Zeit der "Normalisierung", Frankfurt, 1978, pp. 214-222. Ver também sua carta complementar em American Histarical Association Newsletter, september: 15, 1976. 